\title{
OVER DE MOGELIJKHEID VAN INTRANUCLEAIRE KRUISING BIJ HOMOZYGOTEN
}

\author{
door J. P. Lotsy.
}

Kruising is niets anders dan de vereeniging van het ongelijk geaarde; zij is dus bij homozygoten alleen mogelijk indien binnen deze ongelijkgeaarde elementen aanwezig zijn.

Sinds MoRgan's onderzoekingen weten wij, dat zelfs in haploide kernen de chromosomen van ongelijken aard zijn en daarmede wordt kruising, nl. kruising van chromosomen, zelfs bij homozygoten mogelijk.

Deze kan echter niet, zooals bij MoRGAN's crossing-over, in de synapsis plaats vinden omdat kruising alleen mogelijk is, als de beide chromosomen van een paar ongelijk van aard zijn, terwijl deze bij een homozygoot - daar alleen homologe chromosomen een paar vormen - nooit anders dan van gelijken aard kunnen zijn.

De synapsis van een homozygoot met 3 verschillende chromosomen zal er dus uitzien als in onderstaande figuur, in welke de bolletjes de chromomeren van ieder chromosoom aangeven.

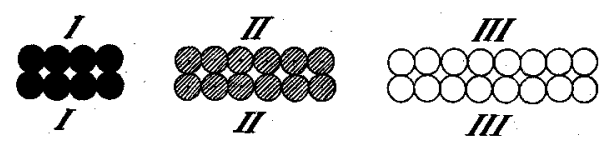

In het gekozen voorbeeld heeft dus de haploide kern in totaal 18 chromomeren, de diploide 36 . Men ziet dadelijk dat, bij de op deze synapsis volgende reductiedeeling, slechts onderling gelijke gametenkernen, of in 't algemeen, gonenkernen kunnen ontstaan, omdat zelfs al vond uitwisseling van chromomeren tusschen de chromosomen van een paar plaats, deze aan den aard van die chromosomen niets zou veranderen. In het synapsis-stadium is dus chromosomenkruising bij homozygoten niet mogelijk. Wel echter in het stadium van den kerndraad, waarin zooals wij weten de chromosomen 
met elkaar verkleven, zoodat de haploide kerndraad - die wij voor de eenvoudigheid kiezen - er in ons geval aldus zal uitzien.

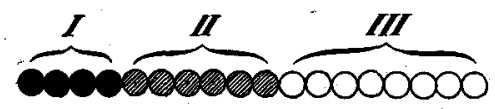

$\mathrm{Nu}$ weten wij, dat deze in den regel breekt op de punten waar de chromosomen zich vereenigd hebben, zoodat $z$ ij in chromosomen van precies denzelfden aard uiteen valt als waaruit zij was opgebouwd, dus in ons geval in de chromosomen:

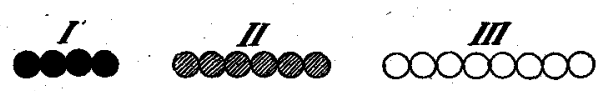

Het is echter zeer goed denkbaar, dat dit eens niet zou geschieden, dat de uitéénvalling bv. aldus zou plaats grijpen.

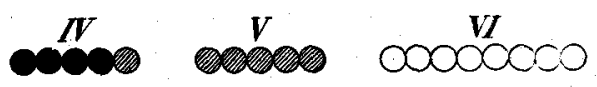

Dat dus het chromosoom I, voortaan als IV aan te duiden, één chromomeer van het chromosoom II had gekregen, waardoor dit laatste, voortaan als $\mathrm{V}$ aan te duiden, nog maar 5 van de oorspronkelijke 6 chromomeren behield, terwijl het chromosoom III, vanwege de symmetrie voortaan als VI aan te duiden, onveranderd bleef, of m. a. w. dat er kruising tusschen de chromosomen I en II had plaats gegrepen, die tot gevolg had de vorming vall de chromosomen IV en $V$.

Zoo'n gameet met dit nieuwe chromosomenstel IV, V, VI zal zich $\mathbf{n u}$, bij zelf bevruchting ${ }^{1)}$ van het betreffende individu, daar zij verre in de minderheid is ten opzichte van de normale gameten van dat individu, bijna zeker met een gameet met het oude chromosomenstel I, II, III vereenigen en dit zal een individu geven, dat hoewel, naar de chromosomen een bastaard, toch uiterlijk niet van een homozygoot individu zal te onderscheiden zijn omdat het in zijn diploide kernen, evenals dit, alle 36 chromomeren bezit. Het zal dus voor homozygoot worden aangezien, maar in zijn gonotokonten zullen de volgende chromosomenparen bij de synapsis worden gevormd.

1) Of bij paring met een ander homozygoot individu met het chromosomenstel I, II, III. 


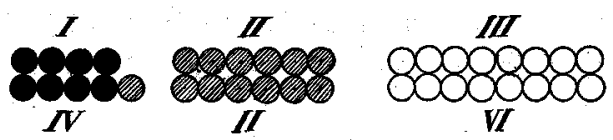

Deze, normaal mendelende, bastaard zal nu door uitwisseling der chromosomen, de volgende 8 gameten geven:
I, II, III
I, II, VI
I, V, III
I, V, VI
IV, V, VI
IV, V, III
IV, II, VI
IV, II, III.

Van deze zijn de gameten I, II, III en IV, V, VI gelijk aan de gameten, waaruit het individu ontstond.

De gameet met het chromosomenstel I, II, VI is gelijk aan die met het chromosomenstel I, II, III, want VI = III.

De gameet met het chromosomenstel IV, V, III is gelijk aan die met het chromosomenstel IV, V, VI, want III = VI.

De gameet met het chromosomenstel I, V, III is gelijk aan die met het chromosomenstel I, V, VI, want III = VI.

De gameet met het chromosomenstel IV, II, VI is gelijk aan die met het chromosomenstel IV, II, III, want VI = III.

Wij behoeven dus slechts de gameten met de chromosomenstellen I, V, VI en IV, II, VI nader te beschouwen en zien dan, dat de eerste een chromomeer verloren, de laatste een chromomeer gewonnen heeft want:

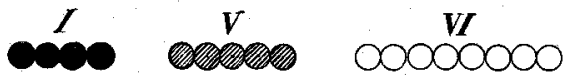

heeft slechts 17 chromomeren; terwijl:
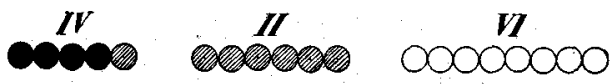

19 chromomeren heeft.

Paren deze dus met aan hen gelijke gameten, dan zullen de producten der eerste zich aan onze oogen als een verlies-mutant, die der laatste als een progressieve mutant kunnen vertoonen.

Hoe zullen deze zich nu gedragen bij terugkruising met den oorspronkelijken vorm? Gaan wij dit eerst eens na voor de verlies-mutant, wier gameten dus een chromomeer minder dan de oorspronkelijke vorm bezitten. Het product der terugkruising zal dan in zijn gonotokonten bij de synapsis de volgende chromosomenparing te zien geven : 

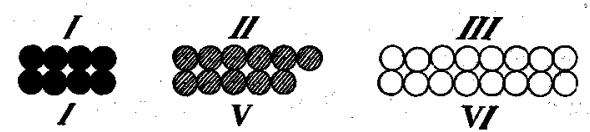

en hieruit kunnen de volgende gameten, die wij met letters willen aanduiden, ontstaan :

A met het chromosomenstel I, II, III.

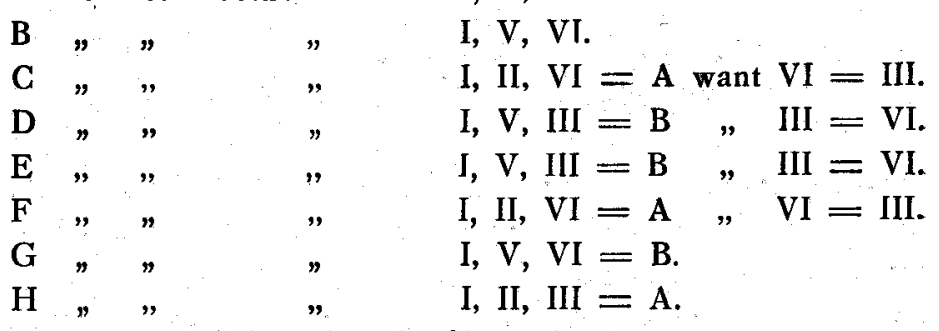

Wij krijgen dus de volgende 64 combinaties:

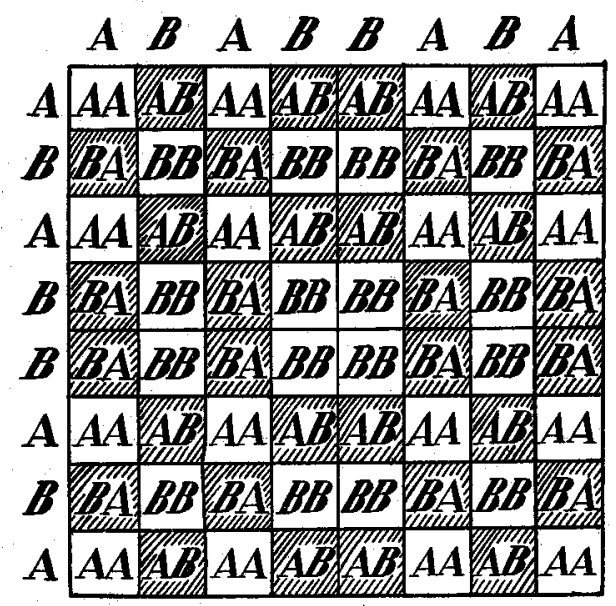

Door de heterozygoten te arceeren, zien wij dadelijk, dat wij op iedere horizontale lijn $4 \mathrm{AB}$ combinaties krijgen, dus $32 \mathrm{AB}$ en op 4 horizontale lijnen telkens 4 AA combinaties, dus 16 AA combinaties en op de 4 andere $4 \mathrm{BB}$ combinaties dus $16 \mathrm{BB}$ combinaties. Wij krijgen dus de verhouding $16 \mathrm{AA}: 32 \mathrm{AB}: 16 \mathrm{BB}$ of : de gewone monohybride mendelsplitsing $1: 2: 1$.

Wij mogen dus besluiten :

Als een gameet, tengevolge van chromosomenkruising, in een homozygoot een chromomeer heeft verloren en daarna met een normale: 
gameet van die homozygoot wordt teruggekruist, treedt in $F_{2}$ monohybride mendelsplitsing op.

Wat zal nu geschieden als wij een gameet die, door chromosomenkruising, in een homozygoot een chromomeer gewonnen heeft met een normale gameet van die homozygoot terugkruisen? In de gonotokont van dat individu zal de synapsis ons de volgende paren toonen :
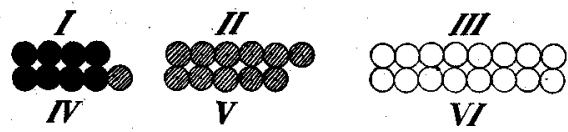

Men ziet dadelijk, dat hier - evenals in het vorige geval - de beide constituenten slechts in één chromosoom verschillen: het paar I, IV, neemt hier de plaats van het paar II, V van het vorige geval in; het resultaat is dus weer: monohybride mendelsplitsing.

De hier beschreven gevallen komen het dichtst bij wat men thans in den regel onder mutanten verstaat, het eerste geval is zelfs zuiver dat van den verlies-mutant, het tweede beantwoordt in zooverre aan dat van een progressieven mutant als inderdaad de gameet een chromomeer of, als men liever wil, een gen meer bezit, dan de homozygote vorm, uit welken zij ontstond.

Het fundamenteele verschil met een progressieven mutant van DE VRIES is echter, dat geen nieuw.vorming van een gen heeft plaats gegrepen: de "progressieve mutant" heeft slechts een, reeds bij de homozygoot aanwezig, gen dubbel en dat verdubbeling belangrijke morphologische gevolgen kan hebben, blijkt uit het feit, dat zygoten met twee X-chromosomen bij de wants Protenor vrouwtjes, die met één X-chromosoom mannetjes geven.

In ieder geval zien wij hier, hoe verlies-mutanten door chromosomen-kruising ook bij homozygoten kunnen ontstaan en eveneens vormen, die althans bij onze tegenwoordige kennis, niet van $\mathrm{DE}$ VRIEs'sche progressieve mutanten te onderscheiden zijn. Wij mogen dus wel besluiten:

Alle in reine Linien waargenomen "mutanten" zïn te verklaren door chromosomenkruising.

Of inderdaad in reine Liniën mutanten ontstaan en of deze werkelijk door chromosomen-kruising ontstaan, is een andere vraag. Daar deze mogelijkheid echter, door de ongelijke geaardheid der chromosomen, voorhanden is, is er geen enkele reden 
meer om uit het optreden van "mutanten" tot nieuw-vorming van genen te besluiten.

Ten slotte zij nog opgemerkt, dat de hier beschreven "mutatie" alleen bij zich geslachtelijk voortplantende organismen kan voorkomen en dus niet kan dienen bij eene poging tot verklaring van het optreden van afwijkende vormen bij organismen, die zich alleen ongeslachtelijk vermogen voort te planten.

Wel is waar kan ook bij een haploid organisme, dat zich alleen ongeslachtelijk vermag voort te planten chromosomen-kruising voorkomen, maar het totaal aantal der chromomeren wordt daardoor niet veranderd.

Alleen door de uitwisseling der chromosomen, die plaats grijpt na de verbinding van twee ongelijk geaarde gameten, kan een chromosomenstel ontstaan met meer of minder chromomeren dan daarin oorspronkelijk aanwezig was.

Aanleiding tot het vormen van ,mutanten", als boven beschreven, is dus - in laatste instantie - chromosomenkruising, maar om deze effect te doen sorteeren is bovendien gametenkruising noodig, daar deze alleen de gelegenheid tot uitwisseling geeft.

Onontbeerlijk is dus de invoeging van een zygote tusschen de aanleiding tot de vorming van en het feitelijk doen geboren worden van de "gemuteerde" gameet, in den regel 'echter vindt de tusschenvoeging van een individu plaats, zoodat men voor de meeste diploiden kan zeggen:

Voor de vorming van "mutanten" is niet alleen chromosomenkruising maar ook kruising van individuen noodig.

Het behoeft wel geen betoog, dat hier onder mutanten alleen verstaan worden individuen, wier vorming berust op het ontstaan van gameten met één chromomeer meer of minder dan de gameet uit welke deze ontstonden en dat de "mutanten" der Oenotheren weer iets geheel anders zijn.

Mid-Ehze, 4 Nov. 1918.

(Ingezonden 6 November 1918). 